SANTOS, MÔNICA PEREIRA; PAULINO, MARCOS MOREIRA (ORGS.). INCLUSÃO EM EDUCAÇÃO: CULTURAS, POLÍTICAS E PRÁTICAS. SÃO PAULO: CORTEZ, 2006. 168 P.

JANETE NETTO BASSALOBRE*

\title{
AS TRÊS DIMENSÕES DA INCLUSÃO
}

O principal objetivo da educação para os estudantes portadores de necessidades educacionais especiais é o de reduzir as condições impeditivas que os impossibilitam de participar de modo pleno na sociedade, possibilitando-lhes o exercício da cidadania. Nesse sentido, a educação inclusiva é um passo decisivo rumo a essa inclusão mais ampla do portador de deficiência, pois busca promover tanto uma aprendizagem factual quanto o desenvolvimento de suas potencialidades.

Inúmeras transformações, sobretudo aquelas relacionadas às posturas adotadas atualmente com relação à deficiência, são necessárias para realmente promover a inclusão que, ainda hoje, após tantas reflexões e estudos, é confundida com a integração, que apenas insere o sujeito na escola, esperando que se adapte a um ambiente escolar já estruturado; a verdadeira inclusão presume o redimensionamento de vários aspectos, tais como estruturas físicas da escola, adaptações curriculares e mudanças de atitude dos educadores, entre outros.

Dentro dessa perspectiva de escola inclusiva e como resultado de um conjunto de trabalhos efetuados no Programa de Pós-Graduação em Educação da UFRJ, por meio da Pesquisa Ressignificando a Formação de Professores para uma Educação Inclusiva, todos os artigos da obra em foco partem, basicamente, da questão dialética exclusão/inclusão, abordada em suas três dimensões: a do desenvolvimento de culturas, a do planejamento de políticas e a da organização das práticas inclusivas.

Mônica Pereira dos Santos, doutora em Psicologia e Educação Especial pelo Institute of Education, da Universidade de Londres, é professora da Faculdade de Educação da Universidade Federal do Rio de Janeiro e fundadora do Laboratório de Pesquisa, Estudos e Apoio à Participação e à Diversidade em Educação (LAPEADE), o qual coordena

\footnotetext{
* Mestre em Educação pela UNISANTOS - Universidade Católica de Santos, psicóloga pós-graduada em Neuropsicobiologia, com especialização em Violência Doméstica e Psicologia Forense. E-mail: janette@litoral.com.br
} 
até o momento. Marcos Moreira Paulino, co-fundador do LAPEADE, é biólogo, professor da rede de Ensino Médio e Mestrando em Educação pela UFRJ.

Por meio de textos estruturados no contexto do corpus teórico que norteia todos os trabalhos, os autores situam a educação no Brasil dentro do conjunto das constantes transformações que ocorrem na sociedade contemporânea, tentando refletir, sob diversos ângulos, sobre uma educação escolar centrada em uma perspectiva realmente inclusiva como um dos fatores para a conquista de uma sociedade efetivamente democrática.

O conjunto da obra, embora tecida em torno de um mesmo eixo coordenador (a dialética inclusão/exclusão sob a ótica de suas dimensões políticas, práticas e de desenvolvimento de culturas) e que transmite em sua totalidade o clima de compartilhamento almejado pela organizadora no prefácio, aborda diversos aspectos da educação inclusiva para os alunos portadores de necessidades especiais. Dessa forma, demos preferência a uma resenha de cunho mais informativo, especificando cada artigo, o que, acreditamos, possibilitará uma visão mais abrangente da totalidade do livro bem como a melhor compreensão dos conteúdos de cada trabalho.

Inicialmente, em "Inclusão em educação: uma visão geral", a partir do raciocínio de que a escola participa de forma determinante nos processos excludentes e de desconsideração à diversidade e de que os fenômenos da inclusão e da exclusão estão estreitamente relacionados, os organizadores postulam a educação inclusiva como um dos instrumentos fundamentais na construção de uma sociedade que possa proporcionar a todos os indivíduos, considerando suas singularidades, a oportunidade de participação nos processos educacionais e sociais em termos igualitários.

Sob o panorama da igualdade distanciada da idéia de homogeneização e contando com a diversidade como fator a ser valorizado, postulam a indispensabilidade da revisão de conceitos estabelecidos, tais como o de currículo, por exemplo, que, do modo como prevalece hoje, distancia-se da realidade do estudante e não favorece a valorização de cada um em suas especificidades, constituindo-se em um modelo padrão e discriminador que compara o estudante a um modelo predeterminado de aluno em vez de avaliar cada um de acordo com o total de sua trajetória.

Júlio Maia dos Santos, em "Dimensões e diálogos de exclusão: um caminho para a inclusão", identifica ações e conceitos que gestam a dialética inclusão/exclusão pelas análises do mercado e da lógica do capi- 
tal (que estabelecem as políticas), das ações culturais escolares (que determinam as culturas) e das práticas pedagógicas utilizadas, tais como a do saber fragmentado que, não contemplando aspectos como a interdisciplinaridade, promovem um sistema que não comporta a criatividade e a emancipação, simplesmente obedecendo as diretrizes de mercado e construindo um modelo de escola no qual os alunos são levados a reproduzirem o sistema dominante, favorecendo a exclusão.

Em "Inclusão e ambiente escolar", Dayse Serra reflete sobre um processo de inclusão escolar que considera ainda em construção, o qual se constitui apenas uma parcela do que a autora chama de "inclusão real e legítima”, que visaria a oferecer as condições de exercício da cidadania. Para tanto, analisa os elementos que considera indispensáveis para o sucesso do processo inclusivo na educação especial: o sujeito incluído, entendido como aquele que necessita ser auxiliado para transpor os obstáculos que o impedem de desempenhar atividades e participar ativamente da sociedade; a família, figura fundamental no processo; e o professor, que deverá ser assessorado para conseguir promover o desenvolvimento das potencialidades dos alunos.

As relações entre inclusão escolar na educação básica e criatividade nas práticas pedagógicas são analisadas por Kátia Xavier da Silva em "Expressão da Criatividade na Prática Pedagógica e a Luta pela Inclusão em Educação: tecendo relações". Apresentando uma reflexão sobre a importância da formação do professor criativo para a construção de culturas de inclusão, tece algumas considerações sobre alguns conceitos de criatividade e estabelece as relações entre inclusão e criatividade, uma vez que tanto uma quanto outra são resultado de necessidades culturais humanas.

O texto seguinte, "Inclusão e processos de formação", assinado por Simone Salgado, destaca também a dimensão pessoal e subjetiva da formação dos professores, postulando-a como fator determinante no processo de inclusão por meio de gerar políticas inclusivas para a construção de novas formas de intervenção do trabalho docente, ilustrando esse processo pela alternância de trechos de uma história infantil e situações vividas por professores "que se equilibram neste caminho incerto [...] mas muito fértil que é a inclusão em educação". (p. 62).

No sexto texto, a partir de pesquisa qualitativa realizada em um centro universitário na Baixada Fluminense, Ana Patrícia da Silva, autora de "O Professor de Educação Física como agente do processo inclusivo", questiona se os docentes do curso em questão se reconhecem como 
agentes no processo inclusivo. Após um enfoque a respeito do conceito de inclusão como processo, a autora caracteriza a disciplina de Educação Física dentro de um panorama bem mais abrangente do que aquele que visa somente às aptidões físicas, apresentando-nos uma descrição da metodologia utilizada no estudo, bem como os resultados obtidos, os quais demonstraram que, embora os professores não possuam ainda um delineamento inclusivo nítido em seus planejamentos, direcionam-se a esse projeto inclusivo e, mesmo que de forma indireta, reconhecem-se como seus agentes.

Em "O coordenador pedagógico como agente para a inclusão", Cristina Nacif Alves inicia seu trabalho assinalando o quanto a ética nas práticas cotidianas precisa abandonar a reprodução de hábitos e atitudes para se afirmar como prática responsável de todo educador em acatar um posicionamento que intente transformação da realidade excludente da escola. Relata detalhadamente o trabalho que vem desenvolvendo para a formação de coordenadores pedagógicos da rede pública municipal da cidade do Rio de Janeiro, a partir de um curso de leitura e escrita, com o intuito de levar esses profissionais a desenvolver uma postura crítica das próprias ações e intervenções.

A autora utiliza os postulados de Vygotsky e Bakhtin com respeito à importância da linguagem na formação dos sujeitos para analisar até que ponto esses coordenadores pedagógicos apropriam-se dos conteúdos transmitidos pelo curso e transformam, com isso, suas próprias representações de ensino e aprendizagem.

"Inclusão na educação: uma reflexão crítica da prática", de Bianca Fogli, Lucindo Silva Filho e Margareth de Oliveira, contextualiza a inclusão do ponto de vista da educação profissional para as pessoas com necessidades especiais, reafirmando a diferença entre os conceitos de integração e inclusão. Os autores discutem os novos desafios relativos às práticas inclusivas dentro da escola como espaço de acesso ao conhecimento, mas também como contexto social para a construção da cidadania.

Vera Lúcia Corrêa e Anakeila Stauffer, em "Educação Inclusiva: repensando políticas, culturas e práticas na Escola Pública", dentro da perspectiva vigotskiana que contempla aspectos como o brincar, o desenho e os aspectos sociais e afetivos, analisam a necessidade da ressignificação das práticas avaliativas excludentes que a escola vem gerando para os portadores de necessidades especiais. As autoras chamam a atenção para as profundas reformas que serão necessárias no currículo e na avaliação para que a aprendizagem desse tipo de aluno possa ser realmente le- 
vada a termo em meio a uma atividade pedagógica que possa desenvolver suas potencialidades.

Cidadania e exclusão são os temas enfocados no último artigo, "Comunicar para viver ou viver para comunicar? Direito mais que natural de qualquer cidadão", em que Margareth de Oliveira, Bianca Fogli e Lucindo Silva Filho procuram refletir tanto sobre o significado desses dois conceitos quanto analisar os fatores que nos tornam cidadãos ou os que nos excluem desse direito, abordando o sistema de comunicação alternativa e ampliada, bem como as deficiências que se beneficiam dessa alternativa especial de comunicação.

Enfim, sob a ótica do combate à exclusão e da construção de uma escola realmente inclusiva, os autores condensam, no presente volume, uma reflexão diversificada dos vários aspectos da realidade educacional para os portadores de necessidades especiais, bem como tentam reunir elementos das dimensões políticas, práticas e do desenvolvimento de culturas que possam estabelecer direções para a Educação Especial que considerem as singularidades e especificidades de cada indivíduo, objetivando, com isso, uma verdadeira prática inclusiva paralelamente à edificação de uma sociedade mais justa e igualitária.

Dessa maneira, a obra resenhada, dirigida a pesquisadores e professores da área, apresenta-se como importante contribuição no âmbito da educação voltada aos alunos portadores de necessidades especiais, da mesma forma que para a ressignificação do entendimento da escola inclusiva em seus vários aspectos. Quanto ao desenvolvimento de culturas e às práticas, o livro recebe profunda atenção dentro da perspectiva de reconstrução de conhecimentos e posturas, deixando entrever a importância do conjunto de ações e representações individuais e grupais que dão sentido aos intercâmbios entre os indivíduos e que, na verdade, constroem a realidade de todos.

Recebido: $28 / 03 / 08$

Aprovado: $14 / 04 / 08$

Contato:

Rua Doutor Manoel Vitorino, 50 - apto. 74

Bairro do Gonzaga

Santos - SP

BRASIL

CEP: 11060-430

E-mail: janette@litoral.com.br 